\title{
Crust and upper mantle structure beneath Bohai Sea inferred from receiver function study*
}

\author{
Yinshuang $\mathrm{Ai}^{*}$ and Zhongyin Shen \\ Key Laboratory of the Earth's Deep Interior, Institute of Geology and Geophysics, \\ Chinese Academy of Sciences, Beijing 100029, China
}

\begin{abstract}
We analyzed teleseismic waveforms recorded by 36 stations near Bohai Sea region and obtained 2248 high quality receiver functions. The crustal thickness $(H)$ and average crustal $v_{\mathrm{P}} / v_{\mathrm{S}}$ ratio $(\kappa)$ as well as the Poisson's ratios beneath 34 stations were estimated using the $H-\kappa$ stacking method. The results indicate that crustal thicknesses near the Liaoning province range from 30.0 to $35.5 \mathrm{~km}$, and the corresponding $v_{\mathrm{P}} / v_{\mathrm{S}}$ ratios vary from 1.72 to 1.89 which corresponds to Poisson's ratio with a range from 0.243 to 0.305 . We also apply a common conversion point (CCP) stacking method of receiver function (RF) to image the upper mantle discontinuity structure beneath Bohai Sea region. Both the $410-\mathrm{km}$ and the $660-\mathrm{km}$ discontinuities (hereafter called the 410 and the 660 ) show clearly in the study region. The transition zone (TZ) thickness shows a different picture from the west to the east of the study region, which is a little bit thicker than that of the global average in the west of longitude $122^{\circ} \mathrm{E}$, however, thinner in the east of longitude $122^{\circ} \mathrm{E}$. We suggested that the dehydration of sinking slab into the lower mantle or a small-scale mantle plume from the lower mantle generated hot upwelling beneath this region.
\end{abstract}

Key words: receiver function; crustal thickness; upper mantle discontinuity CLC number: P315.2 Document code: A

\section{Introduction}

Receiver function (RF) methods have been widely used to study the interior structure of the Earth since they were first introduced to seismology (Langston, 1977; Vinnik, 1977). Teleseismic P waveform contains more information about the Ps converted wave and its multiples from discontinuities in the crust and mantle, which can be used to obtain the average thickness and the Poisson's ratio of the crust by the $H-\kappa$ stacking of RF method (Zhu and Kanamori, 2000) and get the detail structure of the upper mantle discontinuities by the common converted point $(\mathrm{CCP})$ stacking of RFs (Zhu, 2002). The crustal thickness and the Poisson's ratio are important parameters for understanding the composition and evolution of the crust. In the same way, the topography of the upper mantle discontinuities and the transition zone thickness (TZT) can provide

\footnotetext{
* Received 1 September 2010; accepted in revised form 1 January 2011; published 10 February 2011.

* Corresponding author. e-mail: ysai@iggcas.ac.cn

(C) The Seismological Society of China and Springer-Verlag Berlin Heidelberg 2011
}

temperature constraints in the mantle transition zone (MTZ), therefore, it can give some clues to study the dynamics between the subducting slab and the surrounding upper mantle.

Located near the western Pacific subduction zone, Bohai Sea (including the surrounding regions) provides an ideal region to investigate the present status of $\mathrm{Pa}-$ cific subducted slab. Regional $\mathrm{P}$ wave tomography showed that the Pacific slab turned to be stagnant in the MTZ (Huang and Zhao, 2006). However, RF studies revealed the evidence of the slab accumulation in the MTZ and locally penetration into the lower mantle in the similar region (Ai et al., 2003; Li and Yuan, 2003). Thus, the status and dynamics of Pacific slab in the transition zone beneath Bohai Sea remained controversial. In addition, the crustal Poisson's ratio was still poorly constrained beneath Bohai Sea due to the lack of seismic data.

In this study, we used receiver functions stacking techniques to study the crustal and mantle structure beneath Bohai Sea basing on a large amount of waveform data from teleseismic events recorded by 36 stations in Liaoning experiment (Figure 1). Firstly, due to the 
Poisson's ratios can be used to constrain the composition of the crust in the study region, therefore, we applied the $H-\kappa$ stacking scheme (Zhu and Kanamori, 2000) to determine the distributions of the average crustal thickness and Poisson's ratios under each station simultaneously by using the direct P-to-S phase and the later multiple PpPs and PpSs phases from the Moho. Secondly, in order to discuss the relationship between mantle discontinuities and thermal anomalies in the study region, we used the common converted point (CCP) stacking of RFs (Zhu, 2002) to study the topography of the 410 and 660 as well as the TZT with high lateral resolution.

\section{Data and methods}

\subsection{Data}

In this study, we used seismic events recorded by two networks, Liaoning Seismic Network (LSN) and
Bohaiwan Seismic Network (BSN) (Figure 1). LSN, deployed in 1999 by the Earthquake Administration of Liaoning province, includes four broadband and 12 short period permanent stations (Figure 1). All of stations in this network have operated continuously, and record at a rate of 50 samples per second with three components. The data from this network used in this study span from July 1999 to December 2003. BSN, operated from May 2005 to May 2006 by the author's group from the Institute of Geology and Geophysics, Chinese Academy of Sciences (IGGCAS), consists of 20 portable broadband stations with Guralp CMG-3ESP sensors and Reftek 72-A digitizers. We selected teleseismic events from all above stations in the distance range between $30^{\circ}$ and $90^{\circ}$ with magnitude greater than 5.8 for the RF analysis (Ai et al., 2008).

\subsection{Receiver function isolation}

We isolated RFs for each event-station pair in the following ways. Firstly, we visually checked each event

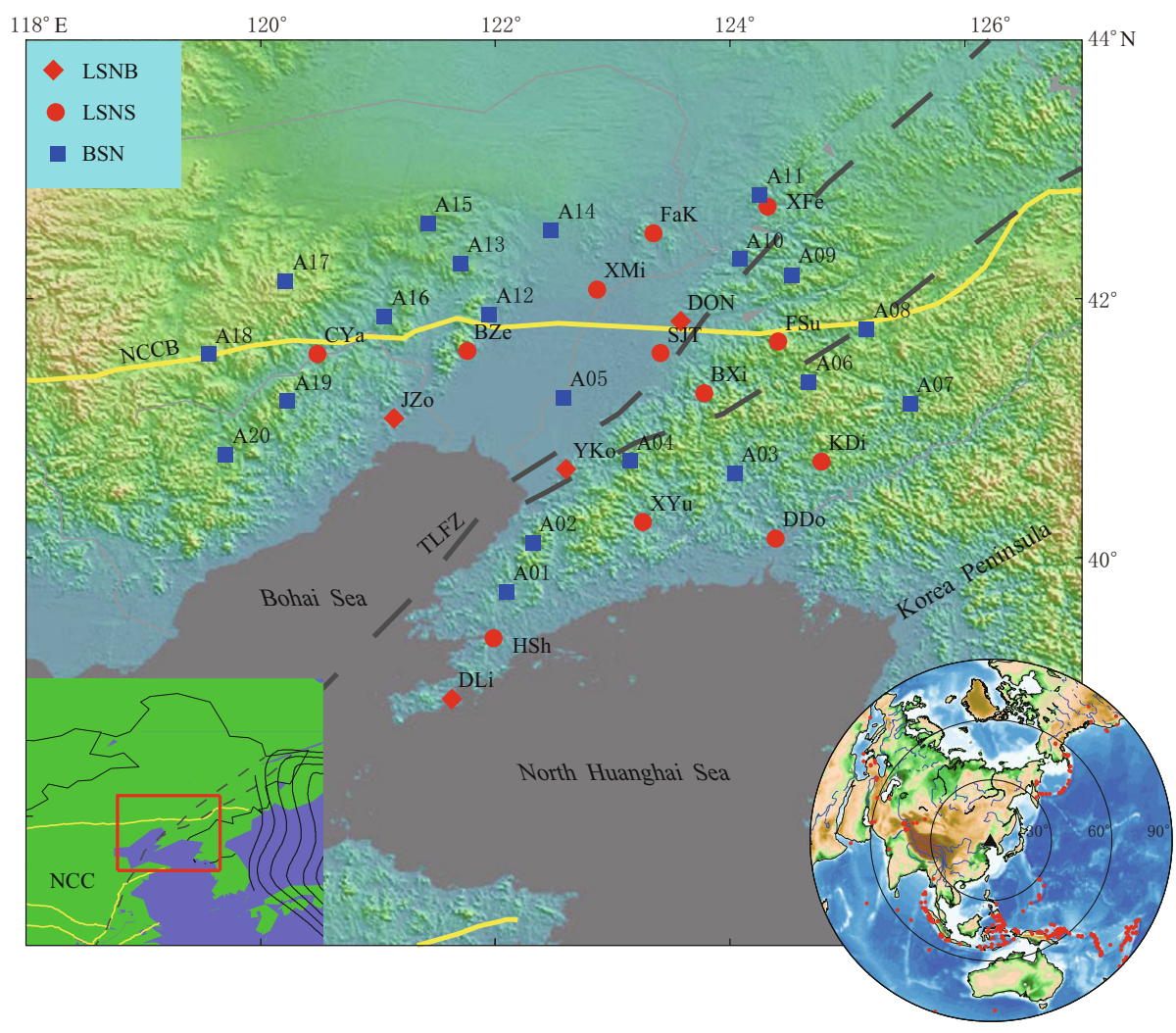

Figure 1 Map showing the study region in eastern China and the seismic stations used in this study (see also the inset). Locations of seismic stations are shown by blue squares for broadband stations of BSN, red squares for LSNB-broadband stations of LSN, red circles for LSNS-short-period stations of LSN, respectively. NCCB and TLFZ denote North China Craton boundary and Tanlu fault zone, respectively. Station codes are shown near stations with three letters. In the down-left inset, lines denotes the depth contours of the subducting Pacific slab along Japan Trench (after Gudmundsson and Sambridge, 1998). Epicenter distribution of teleseismic events used in this study is shown in the down-right inset with red dots. 
to ensure that it was high-quality recording and had clear first P-wave arrival for three components. Secondly, we cut the selected event from $20 \mathrm{~s}$ before to 100 $\mathrm{s}$ after the first $\mathrm{P}$ wave arrival, and used a $2.5 \mathrm{~Hz}$ Gaussian parameter to calculate RFs by the maximum entropy deconvolution method (Ai et al., 2003; Wu et al., 2003). Finally, we visually selected records with high signal-to-noise ratios for each station to ensure that the P-to-S converted phase from the Moho and its two later multiple phases are present. In order to study the crust and upper mantle structures beneath stations, a secondorder zero phase Butterworth bandpass filter with corner frequencies $0.03-1.0 \mathrm{~Hz}$ and $0.03-0.3 \mathrm{~Hz}$ were applied to all RFs, respectively. As a whole, we obtained 2248 reliable RFs, 664 from BSN and 1584 from LSN, respectively. These RFs were isolated from 315 teleseismic events (Figure 1).

\subsection{Methods}

In this study, we used two standard RF methods, $H-\kappa$ and CCP stacking techniques (Zhu and Kanamori, 2000; Zhu, 2002) to study the interior structure of Bohai Sea region.

Previous studies indicated that the crustal thickness and $v_{\mathrm{P}} / v_{\mathrm{S}}$ ratio can be jointly estimated by using the converted phase from the Moho and its multiple reverberations within the crust (Zandt and Ammon, 1995). Since it was difficult to identify the Moho Ps and its multiples and to measure their arrival times on a RF trace, the auto-searching algorithm, $H-\kappa$ method, which sums the amplitudes of the RFs at the predicted arrival times of Ps and its multiple phases, has been developed to best estimate crustal thickness $(H)$ and $v_{\mathrm{P}} / v_{\mathrm{S}}$ ratio $(\kappa)$ simultaneously (Zhu and Kanamori, 2000). In this study, we used $H-\kappa$ method to estimate the crustal thickness $(H)$ and $v_{\mathrm{P}} / v_{\mathrm{S}}$ ratio $(\kappa)$ beneath the stations.

We used the CCP stacking of RFs (Zhu, 2002; Ai et al., 2005) to study the 410 and 660 as well as TZT beneath the Bohai Sea region. The CCP method includes the following processes. First, based on a known velocity model, we calculated the depth domain raypath of each RF. Then, we assigned the amplitude at each point on the RF to its ray-path position where the P-to-S conversion was assumed to exist. Finally, we divided the studied profile into bins and stacked all amplitudes in the same bin and smoothed them by considering the Fresnel zone size of the ray in the specific depth (Zhu, 2002; Ai et al., 2005).

\section{Crustal thickness and Poisson's ratio}

When using the $H-\kappa$ stacking method, we should consider several key parameters in advance. The first one is the average crustal $\mathrm{P}$ velocity (Zhu and Kanamori, 2000) near the study region. Based on the previous studies from Liaoning province (Lu et al., 2005), we used an average crustal $\mathrm{P}$ velocity of $6.1 \mathrm{~km} / \mathrm{s}$ as prior parameter in this study. Secondly, the ranges of crustal thickness and $v_{\mathrm{P}} / v_{\mathrm{S}}$ ratio for each station should be given before the $H-\kappa$ stacking method was used. Previous studies show that crustal thicknesses change from $30 \mathrm{~km}$ to $34 \mathrm{~km}$ in the Liaoning province (Lu et al., 2005). Therefore, in $H-\kappa$ stacking of this study, we constrained the crustal thicknesses from $25 \mathrm{~km}$ to 45 $\mathrm{km}$ for each station. For $v_{\mathrm{P}} / v_{\mathrm{S}}$ ratio, we limited it between 1.6 and 2.0. Thirdly, we should assigned weights for the P-to-S converted phase from the Moho and its later multiples. The highest weight was assigned to the P-to-S converted phase from the Moho because of its highest signal-to-noise ratio. We finally used 0.7 for the P-to-S converted phase from Moho, 0.2 for PpPs, and 0.1 for PpSs+PsPs, respectively.

Figure 2 shows two selected profiles of RFs recorded by stations CYa and A01, respectively. We can identify strong converted phases from the Moho at around $4.5 \mathrm{~s}$ and also clearly identify PpPs for both of them. Station CYa (Figure 2a) belongs to the LSN network. Stacking its 109 RFs gives a crustal thickness of $32.2 \mathrm{~km}$ and a crustal $v_{\mathrm{P}} / v_{\mathrm{S}}$ ratio of 1.89 (Figure $3 \mathrm{c}$ ). Station A01 (Figure 2b) belongs to the BSN network. Stacking its 43 RFs gives a crustal thickness of 34.0 $\mathrm{km}$ and a crustal $v_{\mathrm{P}} / v_{\mathrm{S}}$ ratio of 1.76 (Figure $3 \mathrm{~b}$ ). The average travel time curves of the Moho converted and multiply reflected phases are denoted in dashed lines (Figure 2).

As examples of the stacking results, the stacking amplitude images of four stations are shown in Figure 3. Station BXi is a LSN station on the southeast of Liaoning province, stacking $89 \mathrm{RFs}$ results in crustal thickness of $35.5 \mathrm{~km}$ and crustal $v_{\mathrm{P}} / v_{\mathrm{S}}$ ratio of 1.78 (Poisson's ratio of 0.269)(Figure 3a). In the same case, for the BSN station A17, stacking $27 \mathrm{RFs}$ results in crustal thicknesses of 32.8 and crustal $v_{\mathrm{P}} / v_{\mathrm{S}}$ ratios of 1.79 (Poisson's ratios 0.275)(Figure 3d).

Figure 4 shows the crustal thicknesses and Poisson's ratios distributions in Bohai Sea region constrained by $H-\kappa$ stacking. In total, we obtained results of 34 


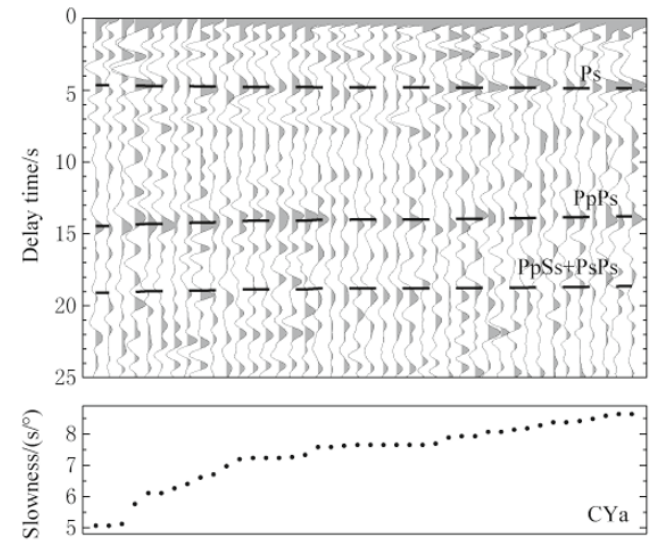

(a)

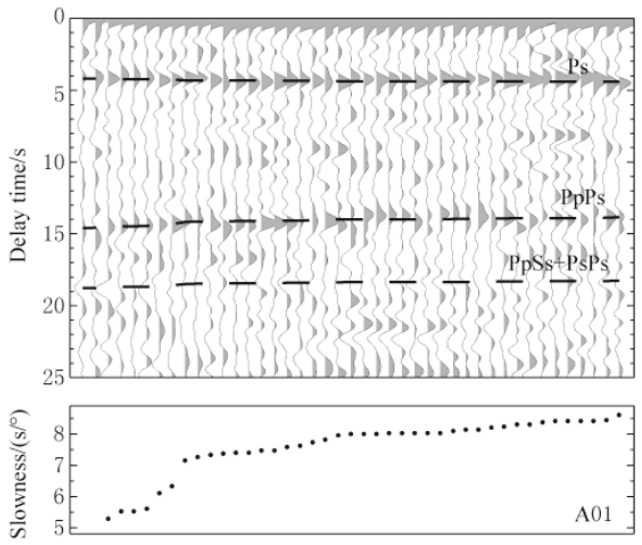

(b)

Figure 2 Receiver function profiles for stations CYa (shown only parts of data) (a) and A01 (b), sorted according to slowness. The dashed lines show the predicted arrival times of Moho converted and reflected waves using the crustal parameters in Figures $3 \mathrm{c}$ and $3 \mathrm{~b}$, respectively.
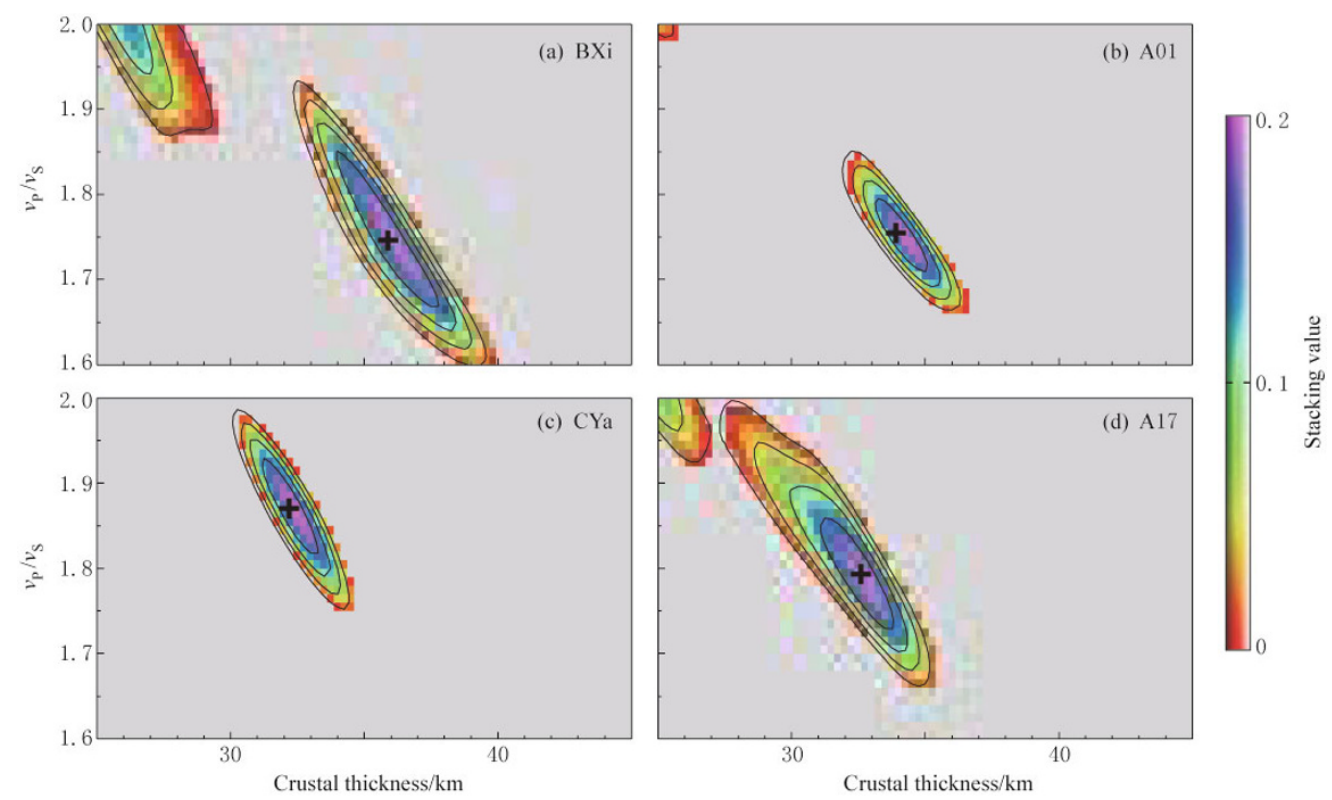

Figure $3 H-\kappa$ stacking results for $v_{\mathrm{P}} / v_{\mathrm{S}}$ ratios and crustal thicknesses under four seismic stations. The station codes are shown in the upper right corner. Cross symbols denote the best estimations when the correct crustal thicknesses and $v_{\mathrm{P}} / v_{\mathrm{S}}$ ratios are used in the stacking.

stations out of 36 stations. Our results indicated that crustal thicknesses near the Liaoning province range from $30.0 \mathrm{~km}$ to $35.5 \mathrm{~km}$, and the corresponding $v_{\mathrm{P}} / v_{\mathrm{S}}$ ratios vary from 1.72 to 1.89 which corresponds to Poisson's ratio with a range from 0.243 to 0.305 . This crustal thickness variation is consistent with previous results obtained from other geophysical surveys ( $\mathrm{Lu}$ et al., 2005).

The relationship between Poisson's ratio and crustal thickness can provide more information about the building processes and tectonic evolution of the continental crust (Ji et al., 2009). NCCB denotes the location of North China Craton boundary (Figure 1) and Figure 5 shows the correlation between Poisson's ratios and crustal thickness in the study region. In Figure 5 , the circles and triangles denote the estimated results from stations in and off the North China Craton (NCC) respectively. The upper and lower solid lines represent the correlation plot results for stations in and off the NCC. In the same way, after excluding some anomaly results from several stations which were labeled the question marks, we get the correlation plot results with 


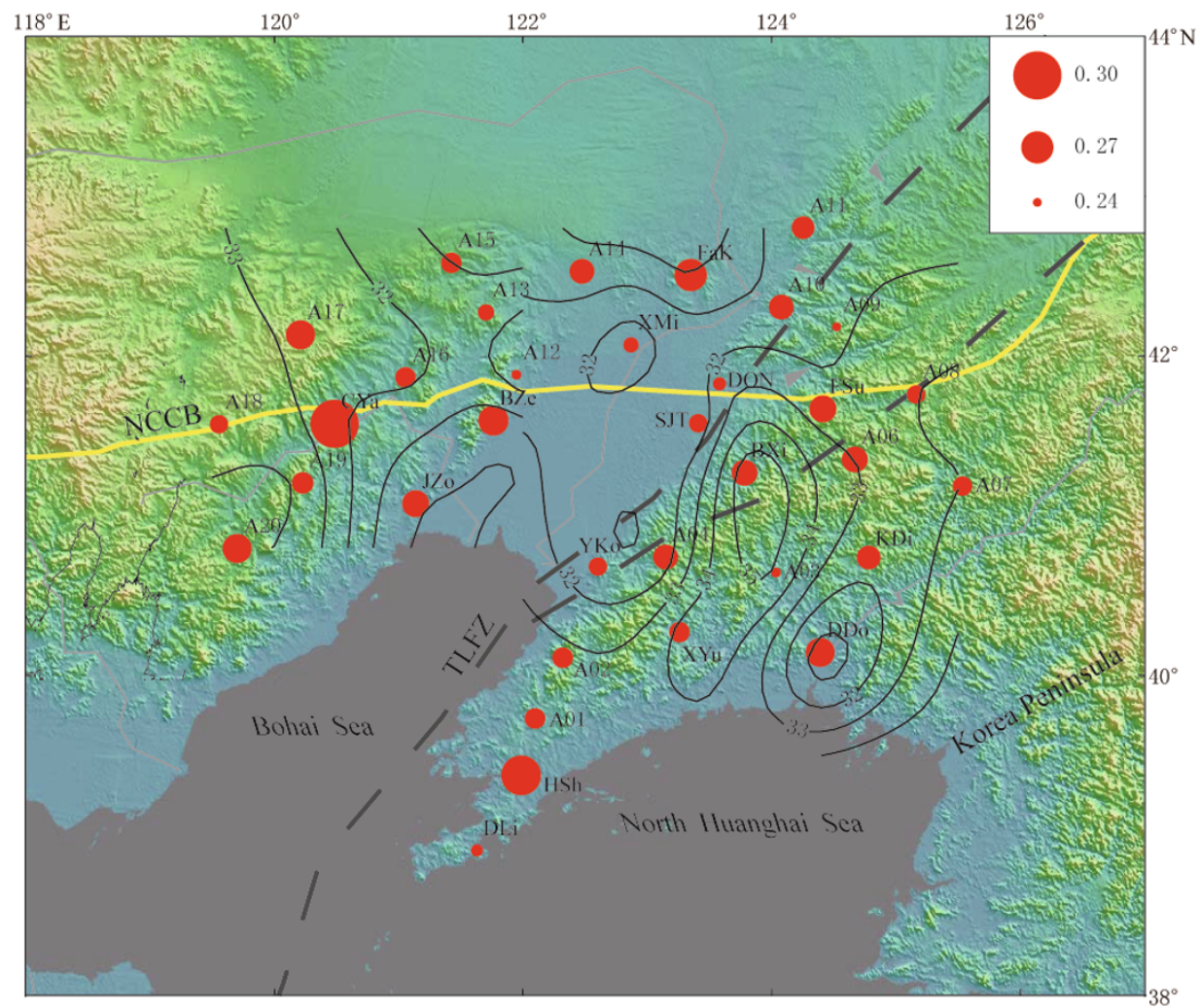

Figure 4 Estimated crustal thicknesses (in km) and Poisson's ratios for 34 stations beneath Bohai Sea region. The contours of the crustal thickness are based on the data of 34 stations.

upper and lower dashed lines for stations in and off the NCC, respectively (Figure 5). In and off the NCC, Poisson's ration decreases linearly with increasing the crustal thickness, however, two plots (solid or dashed lines) have different slopes.

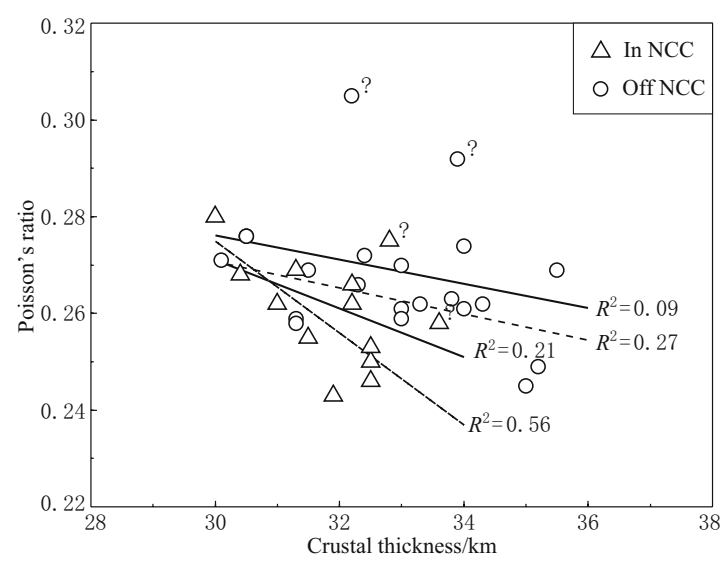

Figure 5 Estimated Poisson's ratios as a function of crustal thickness for 34 stations beneath Bohai Sea region. Triangles and circles denote stations in and off NCC respectively.

\section{Upper mantle discontinuities and TZT}

We performed the CCP stacking along 2D profile using different bin sizes based on different velocity models and smoothing parameters. The 410 and 660 (maximum amplitude part of converted phase) can be traced as continuous positive phases clearly in the study region. For the more details about bin sizes, velocity models and the 410 and 660 structures, we have already given the descriptions in Ai et al. (2008). In this study, we chose 1D IASP91 velocity model with crustal structure modification based on $H-\kappa$ stacking for each station in the CCP stacking. As an example, Figure 6 shows the depth variation for the stacking line at latitude $39.5^{\circ} \mathrm{N}$. The stacking profile is in the south part of the study region, the depths of the 410 change gradually from $410 \mathrm{~km}$ to $420 \mathrm{~km}$ between longitude $120.0^{\circ} \mathrm{E}$ and $122.8^{\circ} \mathrm{E}$, and from $413 \mathrm{~km}$ to about $425 \mathrm{~km}$ between longitude $122.9^{\circ} \mathrm{E}$ and $126.0^{\circ} \mathrm{E}$. On the other hand, the depths of the 660 change gradually from $674 \mathrm{~km}$ to 657 $\mathrm{km}$ between longitude $120.5^{\circ} \mathrm{E}$ and $126.0^{\circ} \mathrm{E}$ (Ai et al., 2008). Compared with the IASP91 model (Kennett and 


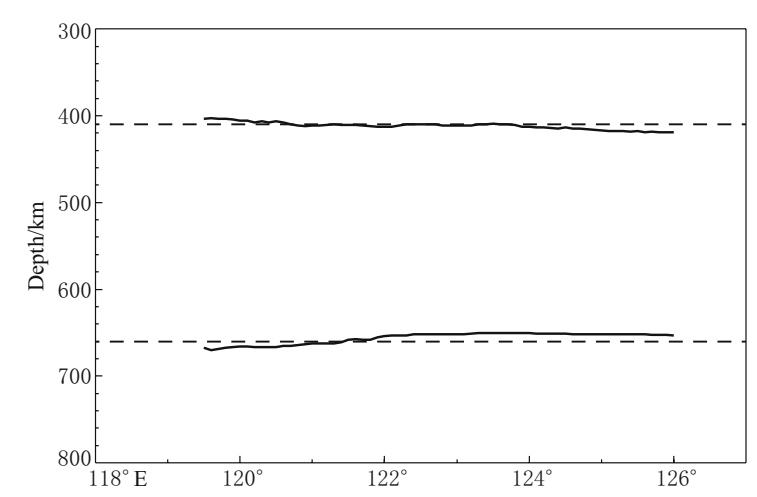

Figure 6 Variation of the 410-km and $660-\mathrm{km}$ discontinities for the stacking line at latitude $39.5^{\circ} \mathrm{N}$.

Engdahl, 1991), the 410 turns to be deeper whereas the 660 turns to be shallower near North Huanghai Sea.

Although the absence of a detailed $3 \mathrm{D} \mathrm{P}$ and $\mathrm{S}$ wave velocity structure in the study region, the TZT variation was less affected by the velocity structure above $410 \mathrm{~km}$ and below $660 \mathrm{~km}$. Therefore the TZT variation was considered to be one powerful indicator for the temperature anomaly in the MTZ (Owens et al., 2000). Hence, we determined the depths of the 410 and 660 by picking up the maximum positive amplitude in the bands of $400-440 \mathrm{~km}$ and $640-680 \mathrm{~km}$ in each bin along all stacking profiles. Then, the TZT was calculated by subtracting the depth of the 660 from that of the 410 for each point. During the calculation, only bins with over 100 RFs were selected for analysis. Figure 7 showed the TZT variations. The TZT are a little bit thicker than that of the global average of $250 \mathrm{~km}$ in the west of longitude $122^{\circ} \mathrm{E}$, however, thinner than that of the global value in the east of longitude $122^{\circ} \mathrm{E}$. The thinnest part of TZT was from $230 \mathrm{~km}$ to $235 \mathrm{~km}$, which was located at North Huanghai Sea and Korea Peninsula near the top of the subducted slab (Ai et al., 2008).

\section{Discussion and conclusions}

Using $H-\kappa$ stacking method, we obtained the crustal thickness and Poisson's ratio distribution in Bohai Sea region. Our results indicated that crustal thicknesses near the Liaoning province range from $30.0 \mathrm{~km}$ to $35.5 \mathrm{~km}$, and the corresponding $v_{\mathrm{P}} / v_{\mathrm{S}}$ ratios vary from 1.72 to 1.89 which corresponds to Poisson's ratio from 0.243 to 0.305 . The distribution of Poisson's ratios on the flank of the mountain is rather uniform except stations CYa and HSh which showed high Poisson's ratios. The distribution of crustal thickness shows that the crustal thickness is getting thicker from north to south, with the thickest $35.5 \mathrm{~km}$ beneath station BXi. The crustal thickness variation in the study region is consistent with previous results obtained from other geophysical surveys ( $\mathrm{Lu}$ et al., 2005; Jia et al., 2010).

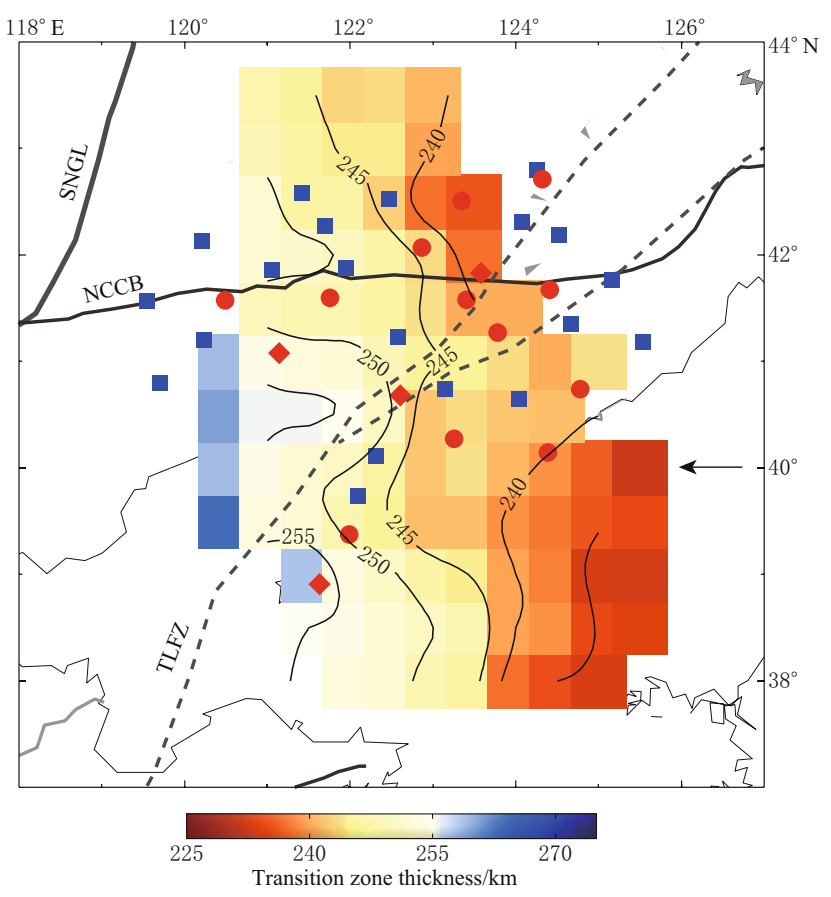

Figure 7 TZT variations calculated on 1D IASP91 velocity model with crustal structure modification based on $H-\kappa$ stacking result for each station. The TZT is determined by subtracting the depth of the 660 from that of the 410 for each bin in the study profile. Contour lines denote the TZT variations. The direction of subducting Pacific slab is shown by the arrow. SNGL denotes South North Gravity Lineament.

From mineral experiment, we know that, a linear correlation of decreasing Poisson's ratio with increasing $\mathrm{SiO}_{2}$ is observed for granitoids (Christensen, 1996). Moreover, a correlation of increasing Poisson's ratio with increase in the anorthite content of plagioclase feldspar is found (Christensen, 1996). Therefore, the higher Poisson's ratios for stations CYa and HSh may be attributed to decreasing $\mathrm{SiO}_{2}$ and increasing calc-alkaline contents in the crust. In our study, the Poisson's ratio gently decreases with increasing crustal thickness (Figure 5) both in and off NCC. Simliar to the previous study in the Baoding-Datong and GuantingZhangjiakou (Ji et al., 2009) regions, this phenomenon is considered as the result from simultaneous underplating of mafic magmas from partially molten upper mantle into deep crust (Ji et al., 2009). 

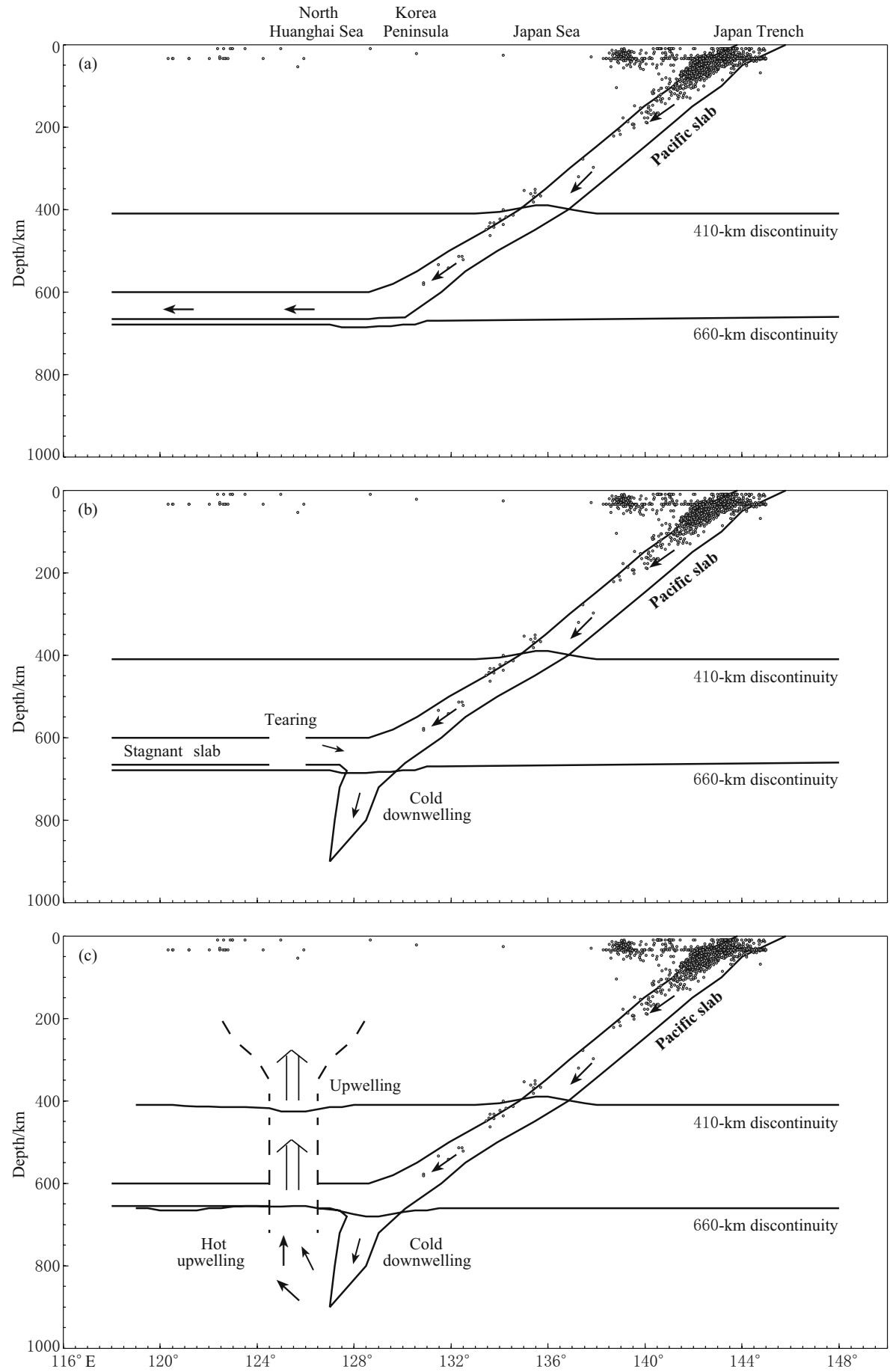

Figure 8 A sketch map showing a small scale convection production. (a) The subducting Pacific slab is subhorizontally deflecting or flattening in the MTZ, which causes a broad depressed 660 and thick TZT in eastern China. (b) Part of slab sinks to the lower mantle which drags the flattened slab backward and broken up. (c) A small scale hot convection occurs, which produces hot upwelling in the upper mantle. Dots show earthquake hypocenters which occurred within latitudes between $38^{\circ} \mathrm{N}$ and $42^{\circ} \mathrm{N}$ at depths of over $50 \mathrm{~km}$ from 1980 to December 2008.

From seismic tomographic results, we can see that the stagnant part of the subducting or younger slab shows fast anomaly dominance in the P-wave image, while the penetrating or older slab displays fast 
anomaly dominance in the shear wave-speed image (Widiyantoro et al., 1999; Gorbatov and Kennett, 2003). We hereby chose several cases of velocity models, which included the IASP91 velocity model, the ISAP91 velocity model crustal structure correction using the results of $H-\kappa$ stacking, the IASP91 velocity model considering the $\mathrm{P}$-wave and S-wave tomographic results of the study region (Fukao et al., 2001; Huang and Zhao, 2006), to verify the TZT variations beneath Bohai Sea and North Huanghai Sea regions. All results demonstrated that the thinning TZ beneath North Huanghai Sea is a reliable feature and the TZ thickness has small variation for the different velocity models (Ai et al., 2008).

The thinning TZ beneath North Huanghai Sea represents the hot temperature anomaly in the TZ. The hot upwelling makes the 660 elevated and the 410 descended, due to the negative and positive Clapeyron slopes for these two discontinuities. Mineral physics studies showed that hydrous minerals in the subducting slabs may exist in the lower mantle, and the dehydration of a subducting slab could happen in the upper part of the lower mantle by decomposition of hydrous ringwoodite (Ohtani et al., 2004). Seismic studies also showed that part of the subducting slab beneath eastern China reaches a depth of $800 \mathrm{~km}$ or more (Bijwaard et al., 1998), and a narrow depressed 660 zone may indicate the slab material piling up at the bottom of the MTZ and sinking locally into the lower mantle (Ai et al., 2003; Li and Yuan, 2003). Recent P wave tomographic images near our study region showed slow anomalies in the upper and lower mantle near the subducting Pacific slab (Zhao et al., 2007). Therefore, we have presented two models, that is, a model of small lateral-scale mantle plumes from the lower mantle, and a model of the dehydration of sinking slab in the lower mantle (Ai et al., 2008).

In order to better understand the model of the dehydration of sinking slab in the lower mantle, we hereby gave a figure explanation as shown in Figure 8. In the first stage, the Japan subducting slabs were subhorizontally deflecting or flattening in the TZ (Ai et al., 2008). In the second stage, with the sufficient trapped slab material increasing in the TZ, part of the rollback slab beneath the east of Korea Peninsula would sink into the lower mantle. Due to decomposition of hydrous ringwoodite (Ohtani et al., 2004), a small-scale convection would generate hot upwelling in the upper mantle and cause the uplifting of the 660 and descending of the 410, together with the thinning TZ beneath the North
Huanghai Sea.

Acknowledgements We gratefully acknowledge the participants of Seismic Array Laboratory of IGGCAS. The GMT software package distributed by Wessel and Smith (1995) was used in plotting figures. This work was supported by the National Natural Science Foundation of China grants 40674028 and 40474022 .

\section{References}

Ai Y, Zhao D, Gao X and Xu W (2005). The crust and upper mantle discontinuity structure beneath Alaska inferred from receiver functions. Phys Earth Planet Inter 150: 339-350.

Ai Y, Zheng T, Xu W, He Y and Dong D (2003). A complex $660 \mathrm{~km}$ discontinuity beneath northeast China. Earth Planet Sci Lett 212: $63-71$.

Ai Y, Zheng T, Xu W and Li Q (2008). Small scale hot upwelling near the North Yellow Sea of eastern China. Geophys Res Lett 35: L20305, doi: 10.1029/2008GL035269.

Bijwaard H, Spakman W and Engdahl E R (1998). Closing the gap between regional and global travel time tomography. J Geophys Res 103: $30055-30078$.

Christensen N I (1996). Poisson's ratio and crustal seismology. J Geophys Res 101: 3139-3 156.

Fukao Y, Widiyantoro S and Obayashi M (2001). Stagnant slabs in the upper and lower mantle transition region. Rev Geophys 39: 291-323.

Gorbatov A and Kennett B L N (2003). Joint bulk-sound and shear tomography for Western Pacific subduction zones. Earth Planet Sci Lett 210: 527-543.

Gudmundsson O and Sambridge M (1998). A regionalized upper mantle (RUM) seismic model. J Geophys Res 103: 7121-7 136.

Huang J and Zhao D (2006). High-resolution mantle tomography of China and surrounding regions. J Geophys Res 111: B09305, doi:10.1029/2005JB004066.

Ji S C, Wang Q and Salisbury M H (2009). Composition and tectonic evolution of the Chinese continental crust constrained by Poisson's ratio. Tectonophysics 463: 1530.

Jia L H, Chong J J, Liu Y Y, Ni S D, Dai J and Wang S (2010). Crustal thickness and Poisson ratio of Liaoning province from receiver function study. Seismology and Geology 32(2): 260-268 (in Chinese with English abstract).

Kennett B L N and Engdahl E R (1991). Traveltimes for global earthquake location and phase identification. Geophys J Int 105: 429-465.

Li X and Yuan X (2003). Receiver functions in northeast China-implications for slab penetration into the lower mantle in northwest Pacific subduction zone. Earth Planet Sci Lett 216: 679-691. 
Langston C A (1977). The effect of planar dipping structure on source and receiver responses for constant ray parameter. Bull Seismol Soc Am 67: 1029-1 050.

Lu Z, Jiang D, Bai Y, Niu X and Meng Z (2005). Exploration and research on the structure of the crust and upper mantle in northeast China. Seismological Research of Northeast China 25(1): 1-8 (in Chinese with English abstract).

Ohtani E, Litasov K, Hosoya T, Kubo T and Kondo T (2004). Water transport into the deep mantle and formation of a hydrous transition zone. Phys Earth Planet Inter 143: 255-269.

Owens T J, Nyblade A A, Gurrola H and Langston C A (2000). Mantle transition zone structure beneath Tanzania, east Africa. Geophys Res Lett 27: 827-830.

Vinnik L P (1977). Detection of waves converted from P to $\mathrm{SV}$ in the mantle. Phys Earth Planet Inter 15: 39-45.

Wessel P and Smith W H F (1995). New version of the Generic Mapping Tools (GMT) version 3.0 released. Eos Trans $A G U$ 76: 329.
Widiyantoro S, Kennett B L N, and van der Hilst R D (1999). Seismic tomography with $\mathrm{P}$ and $\mathrm{S}$ data reveals lateral variations in the rigidity of deep slabs. Earth Planet Sci Lett 173: 91-100.

Wu Q, Tian X, Zhang N, Li W and Zeng R (2003). Receiver function estimated by maximum entropy deconvolution. Acta Seismologica Sinica 16(4): 404-412.

Zandt G, and Ammon C A (1995). Continental-crust composition constrained by measurements of crustal Poisson's ratio. Nature 374: 152-154.

Zhao D, Maruyama S and Omori S (2007). Mantle dynamics of western Pacific and east Asia: Insight from seismic tomography and mineral physics. Gondwana Res 11: 120-131.

Zhu L (2002). Deformation in the lower crust and downward extent of the San Andreas Fault as revealed by teleseismic waveforms. Earth Planets Space 54: 1005-1 010.

Zhu L and Kanamori H (2000). Moho depth variation in southern California from teleseismic receiver functions. J Geophys Res 105: 2969-2 980. 